\title{
Persistent Pulmonary Hypertension of the Newborn, AE
}

National Cancer Institute

\section{Source}

National Cancer Institute. Persistent Pulmonary Hypertension of the Newborn, AE. NCI

Thesaurus. Code C154940.

An adverse event in a newborn characterized by elevated pulmonary vascular pressure in a neonate. 